\title{
On the source inversion of fugitive surface layer releases. Part II. Complex sources
}

\author{
V. Sanfélix*, A. Escrig, A. López-Lilao, I. Celades, E. Monfort \\ Instituto de Tecnología Cerámica-AICE, Universitat Jaume I, Campus Universitari Riu Sec, Avda. Vicent Sos Baynat, 12006 Castelló, Spain
}

\begin{abstract}
The experimental measurement of fugitive emissions of particulate matter entails inherent complexity because they are usually discontinuous, of short duration, may be mobile, and are affected by weather conditions. Owing to this complexity, instead of experimental measurements, emission factors are used to inventory such emissions. Unfortunately, emission factor datasets are still very limited at present and are insufficient to identify problematic operations and appropriately select control measures. To extend these datasets, a source inversion methodology (described in Part I of this work) was applied to field campaigns in which operation-specific fugitive particulate matter emission factors were determined for several complex fugitive sources, some of which were mobile. Mobile sources were treated as a superposition of instantaneous sources. The experimental campaigns were conducted at ports (bulk solids terminals), aggregate quarries, and cement factories, encompassing powder handling operations and vehicle circulation on paved and unpaved roads. Emission factors were derived for the operations and materials involved in these scenarios and compared with those available in the emission factor compilations. Significant differences were observed between the emission factors obtained in the studied handling operations. These differences call into question the use of generic emission factors and highlight the need for more detailed studies in this field.
\end{abstract}

Keywords: Fugitive emissions, Emission factor, Particulate matter, Handling operations, Unpaved roads

\section{Introduction}

Fugitive emissions, as defined by the US regulations (title 40 of the Code of Federal Regulations, sections 70.2 and 71.2), denote a broad category of "emissions which could not reasonably pass through a stack, chimney, vent, or other functionally-equivalent opening". This definition by exclusion reflects the variety and complexity of fugitive sources. Of the pollutant fugitive sources, particulate matter (PM) sources possibly exhibit the greatest complexity.

Indeed, though standard methods for the direct experimental quantification of channelled PM emissions are available (e.g. ISO 9096), which allow accurate and relatively simple routine control, this is not the case with fugitive emissions, probably because of the inherent complexity entailed in fugitive PM quantification 31 and control, owing to different factors:

\footnotetext{
${ }^{*}$ Corresponding author

Email address: vsanfelix@itc.uji.es (V. Sanfélix)
}

- Fugitive PM is transported from its origin by fluctuating wind, rather than at a constant flow rate (as is the case in channelled emissions).

- Almost all fugitive PM emission-generating industrial activities are of a discontinuous nature and short duration, and emission frequency and intensity can vary even within a workday.

- Source position can vary with time - sometimes the source moves continuously along an essentially arbitrary path - .

- Fugitive PM emission rates are often affected by weather conditions (wind speed and direction, atmospheric stability, etc.).

- These operations are often carried out by workers, which introduces a human factor.

Furthermore, dust from one source may become mixed with that from others, because each activity usually involves several overlapping operations, which do 
not necessarily occur in a particular, well-defined sequence. For example, in many bulk solids processing industries, bulk solids are often stored in the open air. This activity usually encompasses several operations: arrival at the bulk solids reception area, piling to form heaps or mounds, transport by a shovel truck or similar vehicle, and finally discharge or unloading of the material for dispatch or subsequent processing. Each of these operations can produce fugitive PM emissions of varying magnitude (Monfort et al., 2011).

Consequently, while channelled PM emissions can be inventoried by experimental measurements at source, fugitive emissions are estimated by means of emission factors (EFs). EFs estimate the PM emission rate based on a unit magnitude that quantifies the intensity of the operation: that is, the emissions are assumed to be directly proportional to that magnitude. In practice, EFs for bulk solids handling are considered to be proportional to the mass of processed material, whereas EFs for vehicle traffic are expressed per unit distance travelled.

At present, there are a number of fugitive PM EFs. The most widely used are those set out in the US Environmental Protection Agency (US EPA) AP-42 compilation (US EPA, 1995, Section 13.2). These fugitive PM EFs are classified into several categories, viz.: (i) paved roads, (ii) unpaved roads, (iii) aggregate handling and storage piles, and (iv) industrial wind erosion. All take the form of predictive empirical equations that depend on a few explanatory experimental parameters.

The AP-42 paved roads PM emissions formula was originally developed by Cowherd et al. (1974), this being revised to incorporate additional tests (US EPA, 1995, Section 13.2). Paved road dust emissions are thought to be one of the main contributors to urban PM pollution (Pant and Harrison, 2013; Amato et al., 2013). Possibly because of this, the determination of paved road PM EFs has been a subject of extensive research (Claiborn et al., 1995; Venkatram et al., 1999; Abu-Allaban et al., 2003; Etyemezian et al., 2003; Ket- 109 zel et al., 2007; Amato et al., 2010, among many others). 110

In contrast, fugitive PM emissions belonging to the 111 other AP-42 categories have drawn much less attention. 112 For example, the category aggregate handling and stor- 113 age piles is used to represent a very extensive array of ${ }_{114}$ operations and materials. Despite such a wide scope, 115 the number of test data considered to derive the EF pre- 116 dictive equation is somewhat limited. In particular, the 117 current formula to estimate these emissions stems from 118 Muleski et al. (1987), which encompasses the results 119 obtained in three test reports that involved coal dump- 120 ing in a coal-fired power plant, drop of prilled sulfur, 121
Table 1: PM EFs for handling of mineral and metal products (EEA, 2016).

\begin{tabular}{cccc}
\hline \multirow{2}{*}{ Industry } & \multicolumn{3}{c}{$\mathrm{PM} \mathrm{EF}\left(\mathrm{g} \mathrm{t}^{-1}\right)$} \\
\cline { 2 - 4 } & $\mathrm{TSP}$ & $\mathrm{PM}_{10}$ & $\mathrm{PM}_{2.5}$ \\
\hline $\begin{array}{c}\text { Mineral } \\
\text { products }\end{array}$ & 12 & 6 & 0.6 \\
\hline $\begin{array}{c}\text { Metal } \\
\text { products }\end{array}$ & 4 & 2 & 0.2 \\
\hline
\end{tabular}

TSP: Total suspended particles

$\mathrm{PM}_{10}$ : $\mathrm{PM}$ less than $10 \mu \mathrm{m}$ in aerodynamic size

$\mathrm{PM}_{2.5}$ : $\mathrm{PM}$ less than $2.5 \mu \mathrm{m}$ in aerodynamic size

s8 and loading of fly ash into open trucks, respectively.

Since the original work by Cowherd and co-workers (Cowherd et al., 1974, 1979; Muleski et al., 1987), relatively few additional studies aimed at deriving EFs for aggregate handling fugitive PM sources have been conducted (Vrins et al., 1994; Muleski et al., 2005; Martín et al., 2007; Hosseini and Stockie, 2016). The scarcity of information is also observed in the EFs set out in the European Environment Agency (EEA) air pollutant emission inventory guidebook (EEA, 2016, Chapter 2.A.5.c) used in European inventories, which contains only generic EFs for these emissions (Table 1).

However, greater detail (in terms of a specific EF for each operation involved in an activity) is deemed of great interest, not just in order to be able to estimate the emissions more accurately but also to be able to identify the most problematic operations and to establish appropriate corrective measures. For example, in a facility's design phase, it would be interesting to be able to determine which facility layout gave rise to the least emissions. This can hardly be done with current information.

Part I of this work (Sanfélix et al., 2015) describes a mathematical framework for the estimation of fugitive emissions. The framework consists of a dispersion model that is flexible enough to deal with the complexity of fugitive PM sources. Part II is a follow-on study in which the model is applied to field campaigns determining specific fugitive EFs for several complex fugitive sources: raw materials loading and unloading at bulk solids wharves, truck circulation on unpaved roads, and raw materials handling with shovel trucks. These sources were studied under actual operating conditions. Sometimes several sources, some of which were mobile, were concurrently involved. 


\section{Calculations}

\subsection{Source inversion calculations}

The calculations performed to obtain the EFs required solving an inverse problem (Isakov, 1990), described in detail in Part I of this work (Sanfélix et al., 2015). The problem basically consisted of calculating the emission rate of an array of pollutant fugitive sources, having determined the concentrations of these pollutants at a (usually limited) number of points in the source surroundings.

The methodology proposed in Part I consisted of solving the problem in two steps. In the first, the pollutant concentration fields were calculated, assuming a unit emission, by means of an atmospheric dispersion model. The proposed model consisted of the numerical solution of the transport equation, which was an equation in partial derivatives solved by the finite volume method. The second step involved the solution of a linear regression problem. Using the superposition principle (Carslaw and Jaeger, 1959), the concentrations at a given point were expressed as a linear combination of those calculated separately for each source. The unknown linear coefficients were the emission rate esti- 172 mates, obtained by linear least squares fitting.

To quantify the goodness of fit and verify the robust- 174 ness of the obtained EFs, a bootstrap technique was used 175 (Efron and Tibshirani, 1993). Since the EFs were de- 176 rived from autocorrelated data (concentration time se- 177 ries), bootstrap replicates were constructed by randomly 178 selecting non-overlapping (12-min long) blocks with 179 replacement among the observations (Künsch, 1989). 180 Furthermore, the least squares method used involved a 181 subjective component through the definition of a thresh- 182 old concentration, below which the concentrations were 183 not considered in the sum of squared residuals (see Part 184 I, Sanfélix et al., 2015). To also account for its influ- 185 ence on the EF, in each bootstrap run, a uniform ran- 186 dom variation $( \pm 50 \%)$ was added to the threshold value. ${ }^{187}$ This procedure enabled confidence intervals to be con- 188 structed for the EFs.

\subsection{Treatment of mobile sources}

Some of the fugitive PM sources involved in the 192 present study were mobile. In Part I, the transport equa- 193 tion was addressed in an Eulerian framework. This 194 framework remains valid for mobile sources, which could have been treated directly, allowing the source to be located at a different point at each instant. The problem with this approach is that breaking down the finite 196 volume domain efficiently is more complex, as it is of 197 interest for the volumes to be smaller near the source. 198

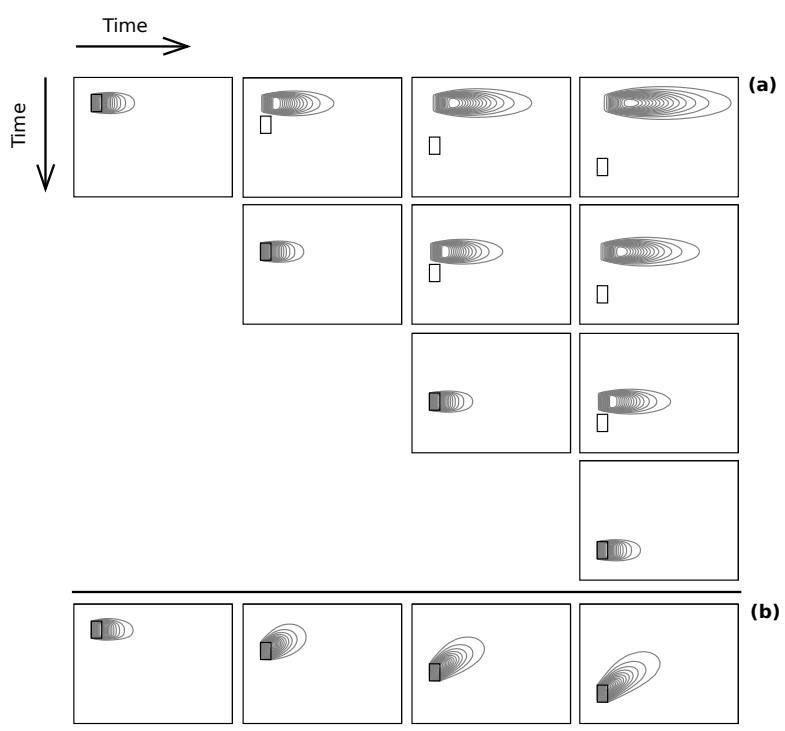

Fig. 1: Illustration of the procedure followed for mobile sources: (a) Each row represents the evolution of a puff. (b) Adding up the corresponding instants yielded the evolution of the continuous source.

It is of course complicated to achieve this effect if the source is continuously moving.

On the other hand, horizontal dispersion was calculated according to the Eckman (1994) interpretation of Taylor's (1921) theorem, which establishes that, in the near-field limit, horizontal eddy diffusivities are proportional to travel time. For static sources, such as those described in Part I, travel time can be calculated from the system of ordinary differential equations proposed by van Ulden (1978). For mobile sources, however, this calculation is not applicable.

The approach used for mobile sources consisted of treating the source as a superposition of instantaneous sources (according to the superposition principle mentioned above). Therefore, the source was assumed to release a series of PM puffs at discrete points along its path. The derived concentration fields of each puff were studied separately and the corresponding instants were then added up to obtain the field produced by the continuous source. The procedure followed is illustrated in Fig. 1. This puff approach also benefitted from actual travel times being readily available for the eddy diffusivity calculation.

\section{Field measurements}

The experimental campaigns were conducted in different scenarios that exhibited environmental issues relating to fugitive PM emissions owing to the type of 
operations conducted and the materials handled: ports (bulk solids terminal), aggregate quarries, and cement factories.

The field measurements were performed by applying the methodology defined in Sanfélix et al. (2015). The field campaigns involved detailed characterisation of the fugitive sources, such that all events producing fugitive PM emissions were appropriately identified. The position, start time, and duration of the emissions were recorded. Differential global positioning systems (DGPSs) were used to measure the position. In addition, in order to be able to revise the record obtained in the field, the experiments were recorded with a video camera. These tools enabled the path of the mobile sources to be determined, as described below.

To perform the calculations, concentrations of PM less than $10 \mu \mathrm{m}$ in aerodynamic size $\left(\mathrm{PM}_{10}\right)$ were measured downwind the source at appropriate distance to resolve the source from the background concentrations. The $\mathrm{PM}_{10}$ concentration time series were obtained by means of continuous recording monitors (GRIMM). The concentrations recorded by three monitors were only available in experiment 1 ; in the other experiments, the concentrations were recorded by just one monitor.

Weather data, such as high-frequency wind speed time series at a given height, friction velocity, and sensible heat flux, were also needed as model inputs. This information was obtained with a sonic anemometer (Delta Ohm HD2003.1). Table 2 shows average meteorological data for the different experiments. Note that experiments 1,3 , and 4 were conducted under unstable stratifications, whereas experiment 2 took place under almost neutral conditions.

\subsection{Experiment 1: Unloading scrap iron from a cargo ship}

Shredded scrap iron was directly unloaded from a ship by a grab onto a bulk solids wharf (Fig. 2), forming a pile of material in the open air. The grab crane used had a capacity of about 23 tonnes. The PM emission was observed to take place mainly during the material unloading operation. Fig. 3 shows the layout of the monitors with relation to the source.

\subsection{Experiment 2: Loading of sodium sulphate onto a cargo ship}

In this experiment, ship loading of sodium sulphate from a conveyor belt on a bulk solids wharf was studied. The material was transported to the belt by dump trucks that discharged the material into a hopper. A conveyor belt then carried the material from the hopper to

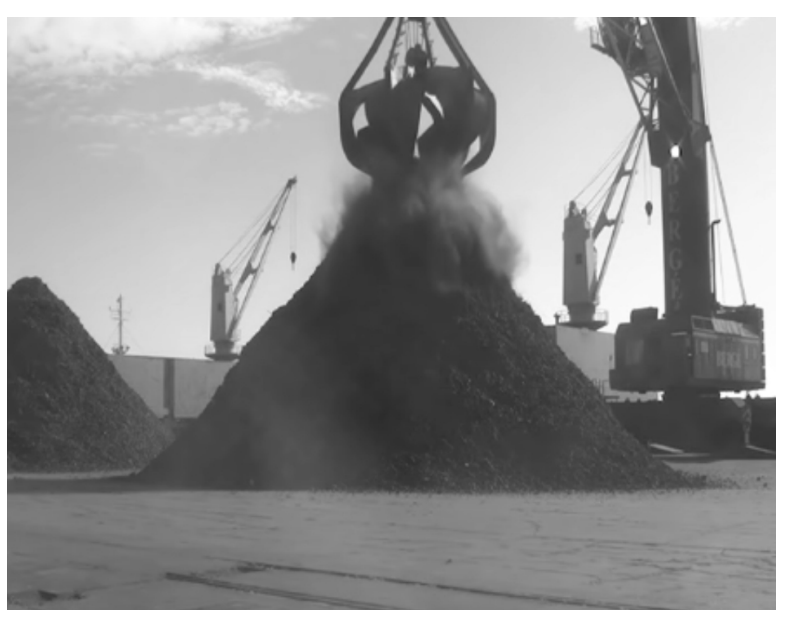

Fig. 2: Direct unloading onto the wharf with a grab.

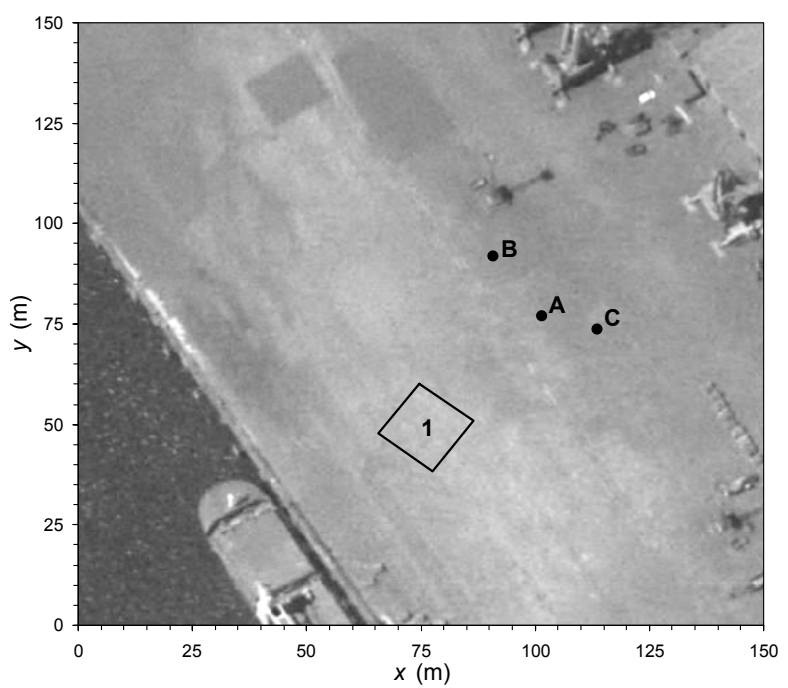

Fig. 3: Position of the source (1) and of the PM monitors (A, B, and C). 
Table 2: Average meteorological parameters in the different experiments.

\begin{tabular}{cccccc}
\hline Experiment & $\begin{array}{c}\text { Wind speed at a } \\
\text { height of } 2.5 \mathrm{~m} \\
\left(\mathrm{~m} \mathrm{~s}^{-1}\right)\end{array}$ & $\begin{array}{c}\text { Wind direction } \\
\left({ }^{\circ}\right)\end{array}$ & $\begin{array}{c}\text { Temperature } \\
\left({ }^{\circ} \mathrm{C}\right)\end{array}$ & Humidity $(\%)$ & $\begin{array}{c}\text { Obukhov length } \\
(\mathrm{m})\end{array}$ \\
\hline 1 & 2.2 & 220 & 25 & 59 & -4.2 \\
\hline 2 & 4.5 & 34 & 20 & 69 & -1900 \\
\hline 3 & 2.1 & 140 & 24 & 43 & -3.7 \\
\hline 4 & 2.0 & 220 & 19 & 34 & -3.5 \\
\hline
\end{tabular}

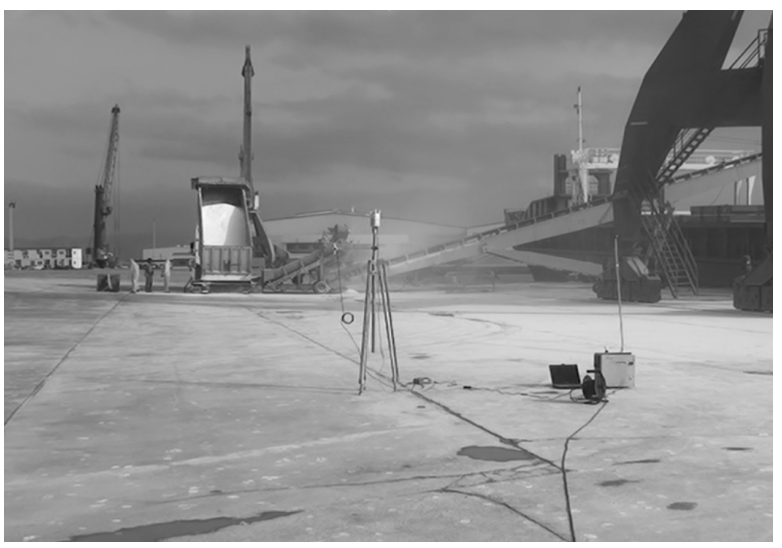

Fig. 4: Truck discharge and conveyor belt transfer.

the vessel (Fig. 4). The PM emission was observed to take place mainly at the transfer point between two belts connected in series. During the experiment, the position of the conveyor belt changed, moving from position 1 to 2, shown in Fig. 5.

\subsection{Experiment 3. Trucks travelling on unpaved roads}

This experiment was carried out at an aggregate quarry and consisted of studying the emissions relating to the transport of blasted material on unpaved roads from the quarry to the crushing machine. Transport was performed by dumpers; the trucks were estimated ${ }_{275}$ to pass at a frequency of about $3 \mathrm{~min}^{-1}$.

The company watered the roads frequently to prevent 277 emissions. As it was intended to study the emissions 278 without corrective measures, a stretch about $120 \mathrm{~m}$ long, 279 in which no watering took place during the experiment, 280 was selected. Fig. 6 shows an arising emission.

To determine the emission point at each instant, one 282 reference point was used at the beginning and at the end ${ }_{283}$ of the selected stretch (Fig. 7) and the instant at which 284

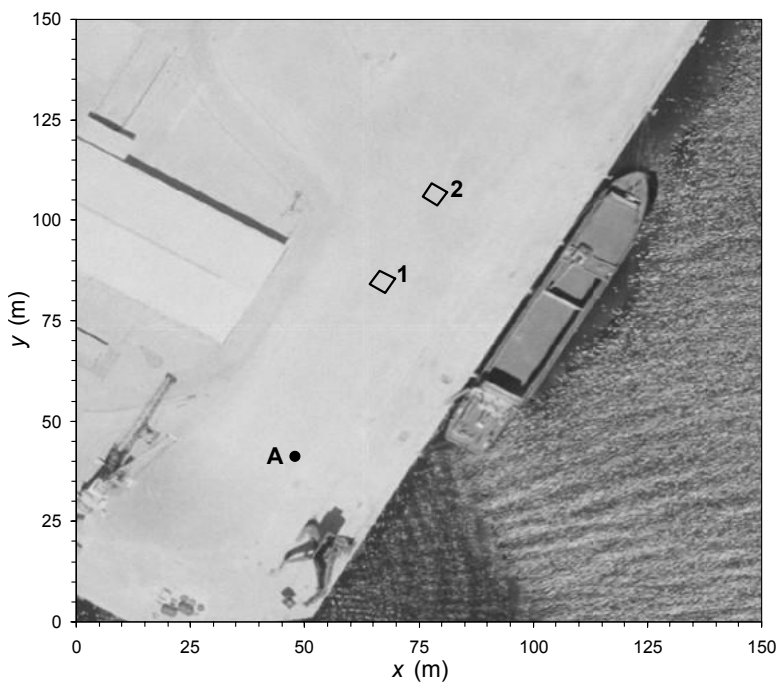

Fig. 5: Positions of the source (1 and 2) and of the PM monitor (A).

the trucks passed these points was recorded. The position of the trucks within this stretch could thus be calculated at each instant, which allowed the subsequent simulations of the corresponding PM emissions and dispersion to be performed.

\subsection{Experiment 4. Raw materials handling with a shovel truck}

This experiment consisted of studying the charging of limestone (stored in the open air) by means of a shovel truck into the feed hopper of a rotary furnace for clinker production for white cement. In this operation, fugitive emissions occurred in shovel loading of the stored material, transport of the loaded material to the hopper, and discharge of the material into the hopper. Discharge into the hopper was considered a fixed emission source, just as material loading, though the latter was performed at different points along the front of the pile, so that the 


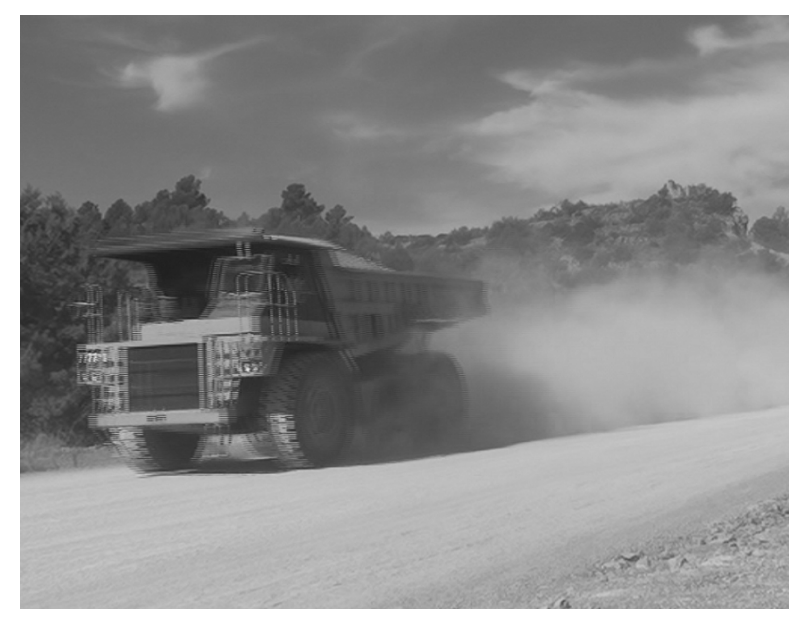

Fig. 6: Dumper travelling on an unpaved road.

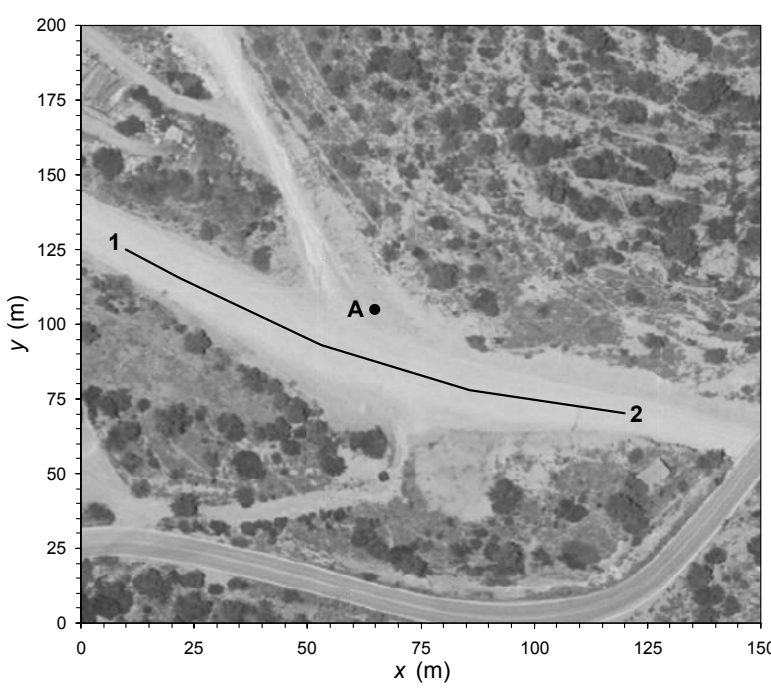

Fig. 7: Truck travel path considered (between points 1 and 2) and position of the PM monitor (A).

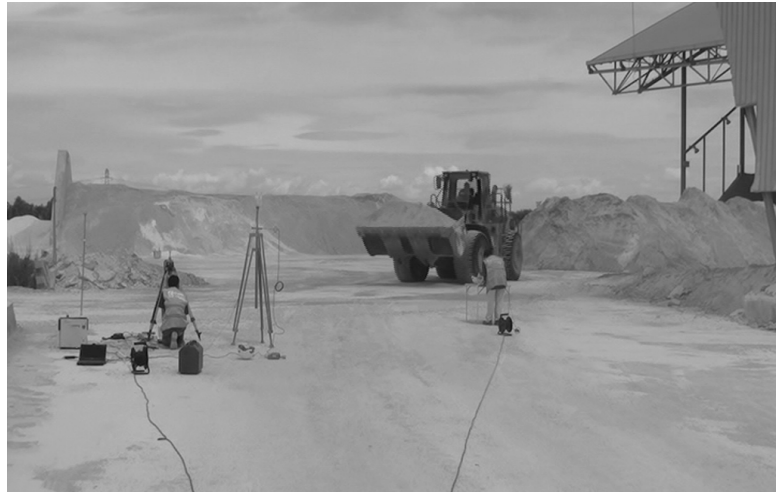

Fig. 8: Shovel loading of the stored material and transport to the hopper.

emission point varied during the experiment. Shovel truck circulation was a mobile emission source.

Fig. 8 shows a photograph of the studied scenario. To address this complex scenario, a fixed/mobile DGPS was used. The mobile antenna was secured onto the shovel truck, which allowed its position at each instant (as well as the points at which the material was loaded) to be continuously recorded. Fig. 9 shows the path travelled by the shovel truck during the experiment.

294

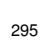
296 297 298 300 301 302 303 304 305 306 307

\section{Results and discussion}

\subsection{Experiment 1: Unloading scrap iron from a cargo ship}

Fig. 10 shows the plots of the experimental $\mathrm{PM}_{10}$ concentrations and of the $\mathrm{PM}_{10}$ concentrations fitted from the calculations with the dispersion model for the 3 devices used in the experimental campaign. The $\mathrm{PM}_{10}$ concentration peaks associated with the scrap iron unloading operations can be readily identified and good agreement is observed between the experimental and the calculated data. There was a systematic bias between the experimental and the fitted concentrations (especially for sampling point A; see Fig. 10), which persisted in the bootstrap replicates. This is an undesirable feature of least squares fitting when extremely short concentration peaks are involved, because it is almost impossible to match exactly the start time and duration of the experimental and the calculated peaks. This may have resulted in a slight underestimation of the EF.

The EFs obtained in the different experiments are detailed in Table 3, together with the confidence intervals computed from the bootstrap samples. The EFs are listed in the units in which they are usually expressed 


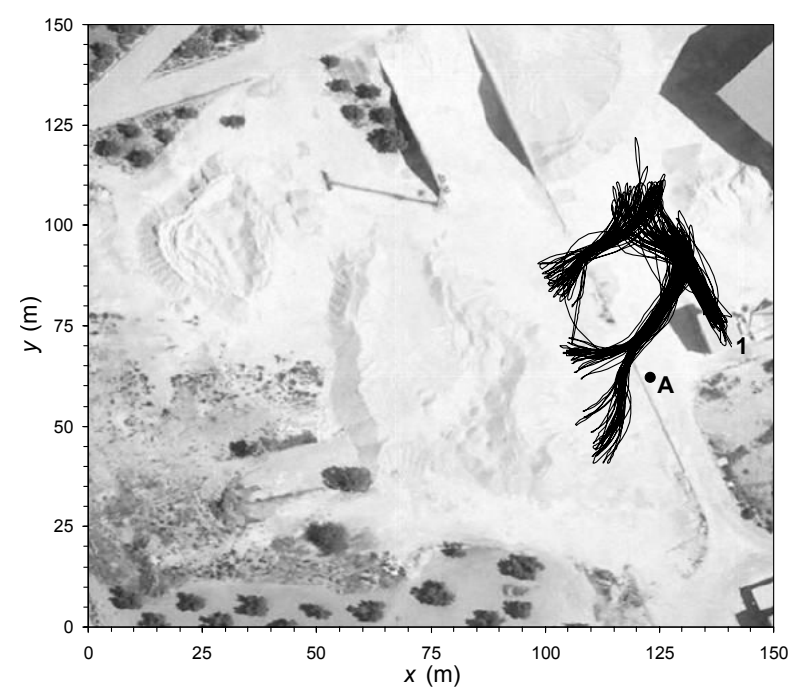
9: Path of the shovel truck (solid line), position of the hopper (1) and of the PM monitor (A).

(in handling operations, in $\mathrm{g} \mathrm{t}^{-1}$ ). The conversion from emission rates $\left(\mathrm{g} \mathrm{s}^{-1}\right)$ to EFs was performed by straightforward calculations based on information collected in the field. This information is summarised in the "considerations" column of Table 3 .

\section{Experiment 2. Loading of sodium sulphate onto a cargo ship}

Fig. 11 shows the experimental and the fitted $\mathrm{PM}_{10}{ }^{373}$ concentrations for the sampling point considered, an ac- 374 ceptable correlation between the calculated values and 375 the experimental data being observed. This agreement ${ }_{376}$ was also reflected in the relatively narrow confidence 377 interval obtained by bootstrapping. Note that at about 378 11:35, the position of the conveyor belt changed, coin- 379 ciding with the period in which the concentrations re- 380 mained relatively low. The distance between the source 381 and the sampling apparatus went from $48 \mathrm{~m}$ to $72 \mathrm{~m}$. $\quad 382$

Truck discharge into the hopper and belt loading of the sodium sulphate onto the ship occurred concurrently ${ }_{38}$ and practically in the same position, so that a specific EF could not be obtained for each of these operations. Table 3 details the joint $\mathrm{PM}_{10} \mathrm{EF}$.

\subsection{Experiment 3. Trucks travelling on unpaved roads}

The fitted concentrations are plotted together with 389 corresponding experimental concentrations in Fig. 12. 390 The recorded $\mathrm{PM}_{10}$ concentration peaks correspond to 391 the passing of the trucks. It was observed in the field 392 that the emission seemed to depend on truck speed. A ${ }_{393}$ hypothetical power-law dependence between the EF and truck travelling speed was therefore assumed. However, the coefficient and exponent obtained in the various bootstrap replicates were found to be correlated, indicating that this dependency was fragile and misleading. A constant EF was therefore used instead, which underwent a skewed variation in the different bootstrap runs (Table 3).

\subsection{Experiment 4. Raw materials handling with a shovel truck}

As indicated previously, three sources were involved in this experiment: material loading, shovel truck circulation, and discharge of the material into the hopper. In the case of shovel truck circulation emission, this appeared to depend on truck movement. Therefore, as had been done for trucks circulating on unpaved roads (experiment 3), the emission was assumed to be a function of truck speed. As in that case, unfortunately, the same problem was identified by bootstrapping and a constant EF was therefore also used. In contrast with experiment 3 , however, where the trucks were always moving, in experiment 4 the truck stood still for some periods, in which no emission would be expected to take place. Shovel truck emissions were therefore only assumed to occur at truck speeds above $0.3 \mathrm{~m} \mathrm{~s}^{-1}$.

The experimental concentrations are plotted together with the fitted concentrations in Fig. 13. In view of the complexity of the sources involved, the agreement is deemed acceptable. In this case, however, EF uncertainty was higher than in the previous experiments (Table 3).

The experimental concentrations exhibited a series of peaks that could not be reproduced in the calculations. However, the field records suggest that they were due to spurious sources that were not considered (leaks were namely identified in a relatively nearby bag filter, which it is suspected could have caused the peaks recorded at about $11: 15$ and 11:50).

\subsection{Comparison with existing EFs}

The EFs obtained in the present study were compared with the most popular EF compilations for PM fugitive emissions inventorying (Table 4), namely the US EPA AP-42 compilation (US EPA, 1995) and the EMEP/EEA guidebook (EEA, 2016). The application of the AP-42 predictive equations for the studied operations required certain input data that were collected during the experiments: material moisture and wind speed for aggregate handling operations, and silt content and vehicle weight for vehicle circulation. 


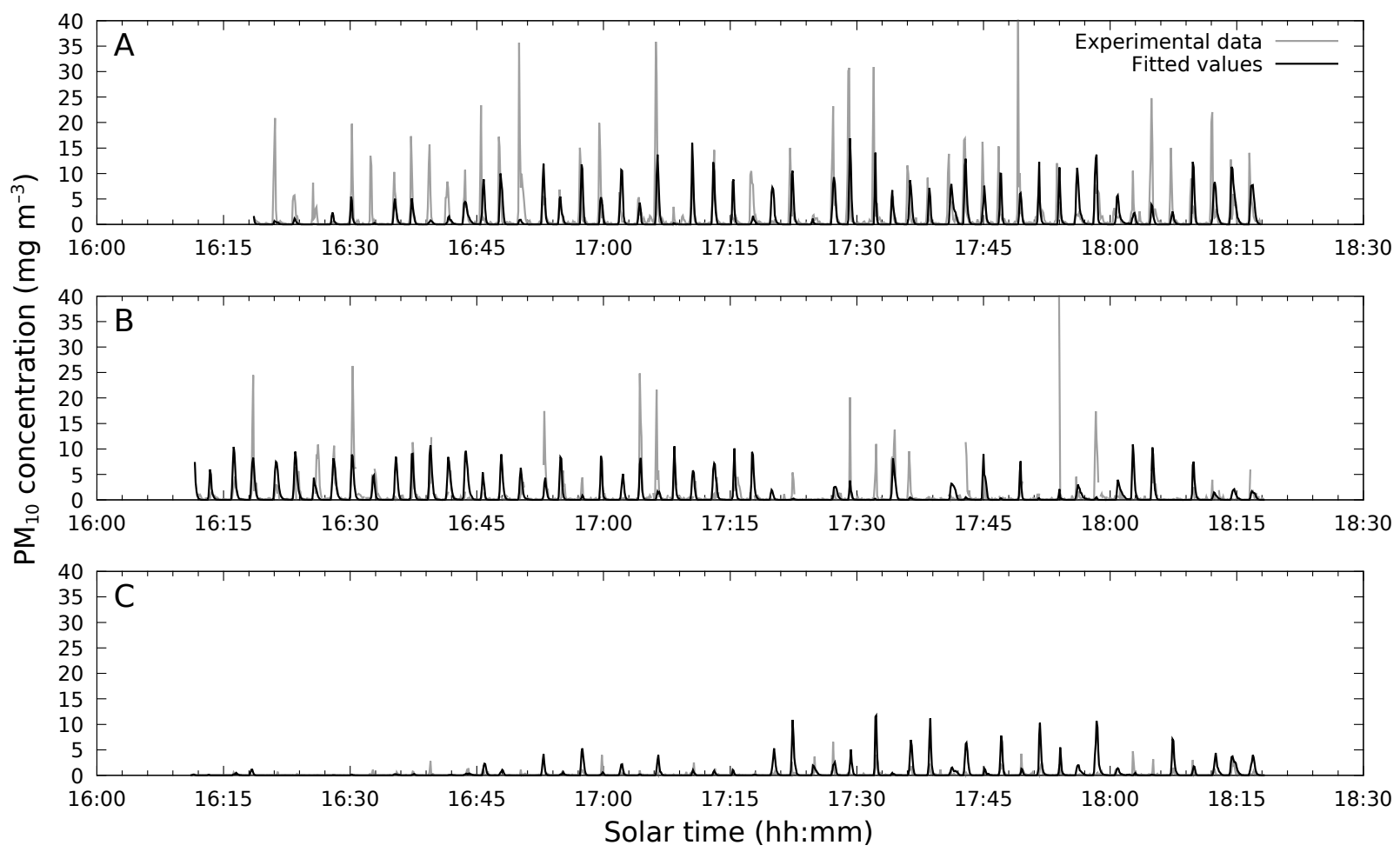

Fig. 10: Experimental concentrations and concentrations fitted with the dispersion model results in experiment 1 at the different selected sampling points.

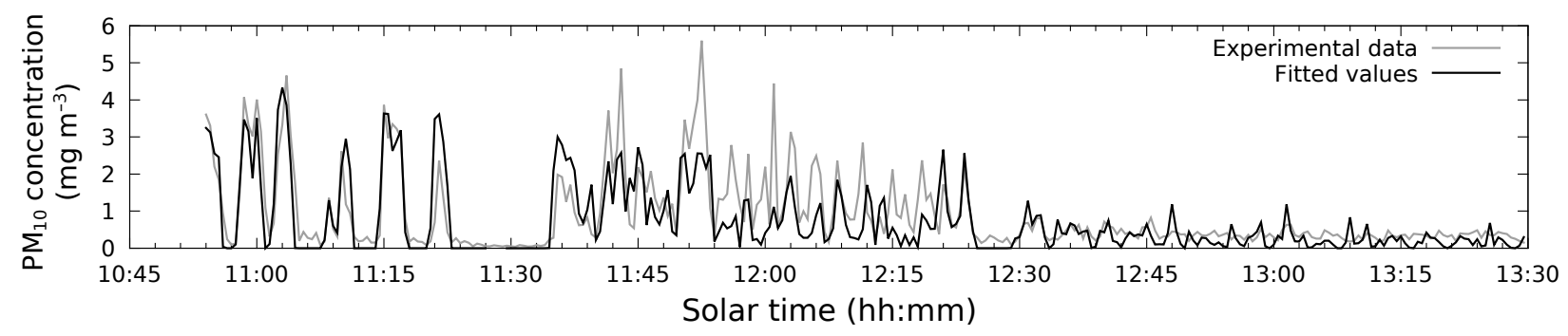

Fig. 11: Experimental concentrations and concentrations fitted with the dispersion model results in experiment 2.

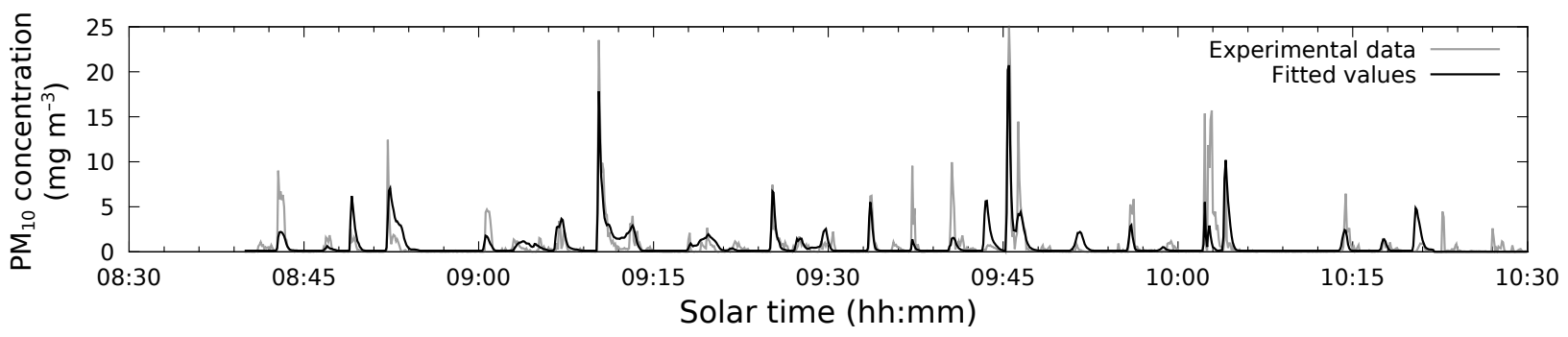

Fig. 12: Experimental concentrations and concentrations fitted with the dispersion model results in experiment 3. 


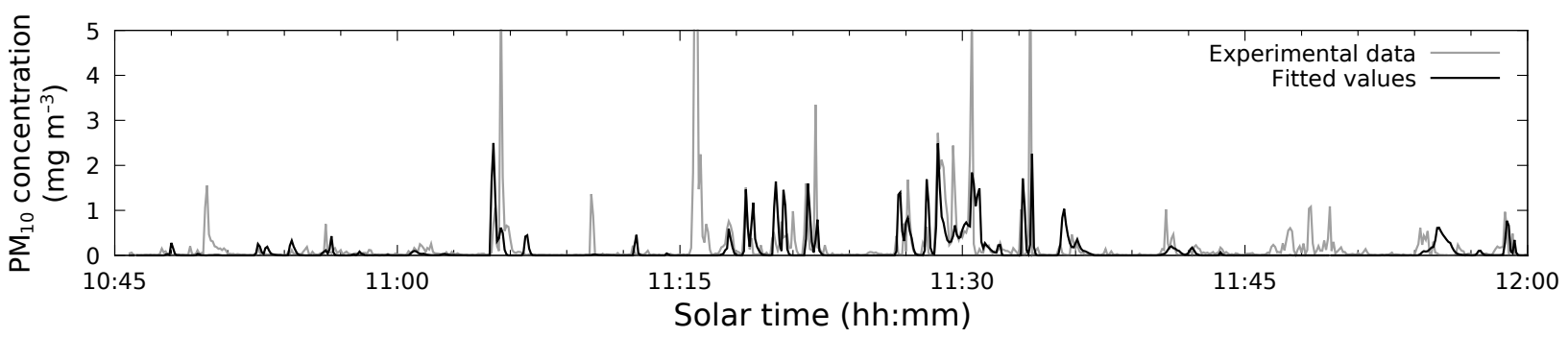

Fig. 13: Experimental concentrations and concentrations fitted with the dispersion model results in experiment 4.

Table 3: $\mathrm{PM}_{10}$ EFs obtained in the different experiments.

\begin{tabular}{|c|c|c|c|c|c|c|}
\hline \multirow{2}{*}{ Experiment } & \multirow{2}{*}{ Operation } & \multirow{2}{*}{$\begin{array}{c}\text { Material/ } \\
\text { Type of road }\end{array}$} & \multicolumn{3}{|c|}{$\mathrm{PM}_{10} \mathrm{EF}$} & \multirow{2}{*}{ Considerations } \\
\hline & & & Expected value & $\begin{array}{c}95 \%- \\
\text { confidence } \\
\text { interval }\end{array}$ & Units & \\
\hline 1 & $\begin{array}{c}\text { Direct } \\
\text { unloading with } \\
\text { grab crane } \\
\text { onto wharf }\end{array}$ & $\begin{array}{l}\text { Shredded scrap } \\
\text { iron }\end{array}$ & 7.3 & $(5.7,9.0)$ & $\mathrm{g} \mathrm{t}^{-1}$ & $\begin{array}{c}\text { Quantity } \\
\text { handled in one } \\
\text { operation: } 23 \mathrm{t} \\
\text { Emission } \\
\text { duration: } 3 \mathrm{~s}\end{array}$ \\
\hline 2 & $\begin{array}{c}\text { Truck } \\
\text { discharge into } \\
\text { hopper }+ \\
\text { mobile } \\
\text { articulated belt }\end{array}$ & $\begin{array}{c}\text { Sodium } \\
\text { sulphate } \\
\left(d_{50}=0.3 \mathrm{~mm}\right)\end{array}$ & 9.6 & $(7.8,10.8)$ & $\mathrm{g} \mathrm{t}^{-1}$ & $\begin{array}{l}\text { Quantity } \\
\text { handled in one } \\
\text { operation: } 25 \mathrm{t} \\
\text { Emission } \\
\text { duration: } 190 \mathrm{~s}\end{array}$ \\
\hline 3 & $\begin{array}{c}\text { Truck } \\
\text { circulation }\end{array}$ & Unpaved road & 530 & $(470,800)$ & $\mathrm{g} \mathrm{km}^{-1}$ & $\begin{array}{c}\text { Range of truck } \\
\text { speed: } \\
8-13 \mathrm{~m} \mathrm{~s}^{-1}\end{array}$ \\
\hline \multirow[t]{3}{*}{4} & $\begin{array}{l}\text { Shovel truck } \\
\text { loading }\end{array}$ & \multirow[t]{2}{*}{$\begin{array}{c}\text { Limestone } \\
\left(d_{50} \approx 10 \mathrm{~mm}\right)\end{array}$} & 0.1 & $<0.4$ & $\mathrm{~g} \mathrm{t}^{-1}$ & $\begin{array}{c}\text { Quantity } \\
\text { handled in one } \\
\text { operation: } 6 \mathrm{t} \\
\text { Emission } \\
\text { duration: } 6 \mathrm{~s}\end{array}$ \\
\hline & $\begin{array}{c}\text { Shovel truck } \\
\text { discharge into } \\
\text { hopper }\end{array}$ & & 0.1 & $<0.4$ & $\mathrm{~g} \mathrm{t}^{-1}$ & $\begin{array}{c}\text { Quantity } \\
\text { handled in one } \\
\text { operation: } 6 \mathrm{t} \\
\text { Emission } \\
\text { duration: } 6 \mathrm{~s}\end{array}$ \\
\hline & $\begin{array}{l}\text { Shovel truck } \\
\text { circulation }\end{array}$ & Paved road & 130 & $(70,170)$ & $\mathrm{g} \mathrm{km}^{-1}$ & $\begin{array}{c}\text { Range of truck } \\
\text { speed: } \\
0-3 \mathrm{~m} \mathrm{~s}^{-1}\end{array}$ \\
\hline
\end{tabular}

$d_{50}:$ median grain diameter $(\mathrm{mm})$ 
In experiment 2, there were two consecutive dropping 444 operations. The overall EF was therefore assumed to 445 be twice the EF from the above compilations. On the ${ }_{446}$ other hand, material discharge in experiment 4 was per- ${ }_{447}$ formed into a hopper with partial enclosure. The emis- ${ }_{448}$ sion abatement effectiveness associated with this partial ${ }_{449}$ enclosure was assumed to be 30\% (Australian Govern- 450 ment, 2012).

The confidence intervals obtained for the handling ${ }_{452}$ EFs exhibited statistically significant differences. In particular, the handling emissions EFs in experiments 2 and 4 differed by a factor of 100 , which was consistent with what had been observed in the field. The ${ }_{454}$ EMEP/EEA guidebook contains only a single-value ${ }_{455}$ EFs for all handling operations involving mineral prod- ${ }_{456}$ ucts. Consequently, the use of such generic EFs might ${ }_{457}$ lead to order-of-magnitude errors in emission invento- ${ }_{458}$ rying. The implications of this outcome are important, because emission inventories subject to order-ofmagnitude errors are inappropriate for establishing priorities in the adoption of control measures.

AP-42 tries to take into account the properties of the materials involved by means of predictive formulas that ${ }_{46}$ depend on the material parameters mentioned above. ${ }_{465}$ However, there are corner cases where these equations ${ }_{466}$ are not even applicable, such as experiment 1 , in which an essentially dry material was involved, and the proposed equation would have predicted an infinite emission. Furthermore, the equation for handling also lacks ${ }_{468}$ explanatory variables relating to the specific operation, 469 even though it is intended to represent any aggregate ${ }^{470}$ dropping operation.

The EF obtained for truck circulation on unpaved 473 roads (experiment 3) was about three times lower than 474 that estimated with AP-42. In constrast, the EF ob- ${ }^{475}$ tained for truck circulation on paved roads (experi- ${ }_{477}$ ment 4) was similar to that calculated with the AP- 478 42 formula. There are no industrial road EFs in the ${ }^{479}$ EMEP/EEA guidebook.

\section{Conclusions}

The flexibility of the mathematical model of pollutant dispersion developed in Part I of this work, as well as the ${ }_{487}$ approach used to deal with mobile sources (superposi- 488 tion of instantaneous sources) and the thorough parame- ${ }^{489}$ terisation of these sources, has allowed complex fugitive $\mathrm{PM}$ sources to be characterised and specific $\mathrm{PM}_{10} \mathrm{EFs}$ to be satisfactorily obtained.

The studied materials were found to exhibit signifi- ${ }^{494}$ cantly different emissions under the handling operation ${ }_{496}^{495}$ conditions used. These differences cannot be explained ${ }_{497}$ in terms of generic EFs as proposed in the EMEP/EEA guidebook for mineral products. Discrepancies were also found between the EFs obtained and those determined using the AP-42 predictive formulas, there even being cases where these formulas could not be applied. These limitations suggest more accurate quantification of fugitive $\mathrm{PM}_{10}$ emissions is needed to enable identification of the most problematic operations in order to select appropriate corrective measures.

\section{Acknowledgements}

Experiment 1 was carried out within the framework of the contract SAFE AND GREEN PORT funded by FEDER Investigación, Desarrollo e Innovación para el Desarrollo de las empresas Fondo Tecnológico 20072013. Experiments 2-4 were supported by the Spanish Ministry of Environment, through the Fundación Biodiversidad, by funding project "Control de las emisiones difusas de material particulado: Propuesta de medidas correctoras". The authors gratefully acknowledge ORIGEN MATERIALES, PORTCASTELLÓ, Puerto de Huelva, and GTD System \& Software Engineering for their support and collaboration in conducting the field measurements.

\section{References}

Abu-Allaban, M., Gillies, J.A., Gertler, A.W., Clayton, R., Proffitt, D., 2003. Tailpipe, resuspended road dust, and brake-wear emission factors from on-road vehicles. Atmospheric Environment 37, 5283-5293.

Amato, F., Nava, S., Lucarelli, F., Querol, X., Alastuey, A., Baldasano, J., Pandolfi, M., 2010. A comprehensive assessment of PM emissions from paved roads: real-world emission factors and intense street cleaning trials. Science of the Total Environment 408, 4309-4318.

Amato, F., Schaap, M., Reche, C., Querol, X., 2013. Road traffic: a major source of particulate matter in Europe, in: Viana, M. (Ed.), Urban Air Quality in Europe. Springer, pp. 165-193.

Australian Government, 2012. Emission estimation technique manual for mining. Version 3.1. Department of Sustainability, Environment, Water, Population and Communities.

Carslaw, H.S., Jaeger, J.C., 1959. Conduction of heat in solids. 2nd ed., Oxford University Press, Londres.

Claiborn, C., Mitra, A., Adams, G., Bamesberger, L., Allwine, G. Kantamaneni, R., Lamb, B., Westberg, H., 1995. Evaluation of $\mathrm{PM}_{10}$ emission rates from paved and unpaved roads using tracer techniques. Atmospheric Environment 29, 1075-1089.

Cowherd, C., Axetell, K., Guenther, C.M., Jutze, G.A., 1974. Development of emission factors for fugitive dust sources. Technical Report EPA-450/3-74-037. US Environmental Protection Agency.

Cowherd, C., Bohn, R., Cuscino, T., 1979. Iron and steel plant open source fugitive emission evaluation. Technical Report EPA-600/279-103. US Environmental Protection Agency.

Eckman, R.M., 1994. Re-examination of empirically derived formulas for horizontal diffusion from surface sources. Atmospheric Environment 28, 265-272. 
Table 4: Comparison of the obtained $\mathrm{PM}_{10}$ EFs with those of existing compilations (US EPA, 1995; EEA, 2016).

\begin{tabular}{|c|c|c|c|c|c|c|}
\hline \multirow{2}{*}{ Experiment } & \multirow{2}{*}{ Operation } & \multicolumn{4}{|c|}{$\mathrm{PM}_{10} \mathrm{EF}$} & \multirow{2}{*}{ Considerations } \\
\hline & & $\mathrm{AP}-42$ & EMEP/EEA ${ }^{\mathrm{a}}$ & Present study & Units & \\
\hline 1 & $\begin{array}{l}\text { Direct unloading } \\
\text { with grab crane } \\
\text { onto wharf }\end{array}$ & Not applicable ${ }^{\mathrm{b}}$ & 2 & 7.3 & $\mathrm{~g} \mathrm{t}^{-1}$ & $M \approx 0 \%$ \\
\hline 2 & $\begin{array}{c}\text { Truck discharge } \\
\text { into hopper }+ \\
\text { mobile } \\
\text { articulated belt }\end{array}$ & $2 \times 14^{b}$ & $2 \times 6$ & 9.6 & $\mathrm{~g} \mathrm{t}^{-1}$ & $\begin{array}{l}M=0.4 \% \\
u=4.5 \mathrm{~m} \mathrm{~s}^{-1}\end{array}$ \\
\hline 3 & Truck circulation & $1700^{c}$ & Not available & 530 & $\mathrm{~g} \mathrm{~km}^{-1}$ & $\begin{array}{l}s=11 \% \\
W=80 \mathrm{t}\end{array}$ \\
\hline \multirow[t]{3}{*}{4} & $\begin{array}{c}\text { Shovel truck } \\
\text { loading }\end{array}$ & $0.5^{\mathrm{b}}$ & 6 & 0.1 & $\mathrm{~g} \mathrm{t}^{-1}$ & \multirow[t]{2}{*}{$\begin{array}{c}M=2 \% \\
u=2.0 \mathrm{~m} \mathrm{~s}^{-1}\end{array}$} \\
\hline & $\begin{array}{l}\text { Shovel truck } \\
\text { discharge into } \\
\text { hopper }\end{array}$ & $0.3^{\mathrm{b}}$ & 4 & 0.1 & $\mathrm{~g} \mathrm{t}^{-1}$ & \\
\hline & $\begin{array}{c}\text { Shovel truck } \\
\text { circulation }\end{array}$ & $150^{\mathrm{d}}$ & Not available & 130 & $\mathrm{~g} \mathrm{~km}^{-1}$ & $\begin{array}{r}s=8 \mathrm{~g} \mathrm{~m}^{-2} \\
W=33 \mathrm{t}\end{array}$ \\
\hline
\end{tabular}

${ }^{\text {a }}$ EMEP/EEA air pollutant emission inventory guidebook (see Table 1).

${ }^{\mathrm{b}} \mathrm{AP}-42$ Chapter 13.2.4: $\mathrm{EF}=0.35 \cdot 1.6 \frac{(u / 2.2)^{1.3}}{(M / 2)^{1.4}}$ where $u$ is wind speed $\left(\mathrm{m} \mathrm{s}^{-1}\right)$, and $M$ is material moisture content $(\%)$.

${ }^{c}$ AP-42 Chapter 13.2.2: $\mathrm{EF}=423\left(\frac{s}{12}\right)^{0.9}\left(\frac{W}{3}\right)^{0.45}$ where $s$ is silt content $(\%)$, and $W$ is mean vehicle weight $(\mathrm{t})$.

${ }^{\mathrm{d}} \mathrm{AP}-42$ Chapter 13.2.1: $\mathrm{EF}=0.62 s^{0.91} W^{1.02}$ where $s$ is silt loading $\left(\mathrm{g} \mathrm{m}^{-2}\right)$, and $W$ is mean vehicle weight $(\mathrm{t})$. 
EEA, 2016. EMEP/EEA air pollutant emission inventory guidebook Technical Report. European Environment Agency.

Efron, B., Tibshirani, R.J., 1993. An introduction to the bootstrap. Chapman \& Hall, Boca Raton.

Etyemezian, V., Kuhns, H., Gillies, J., Chow, J., Hendrickson, K. McGown, M., Pitchford, M., 2003. Vehicle-based road dust emission measurement (III): effect of speed, traffic volume, location, and season on $\mathrm{PM}_{10}$ road dust emissions in the Treasure Valley, ID. Atmospheric Environment 37, 4583-4593.

Hosseini, B., Stockie, J.M., 2016. Bayesian estimation of airborne fugitive emissions using a Gaussian plume model. Atmospheric Environment 141, 122-138.

Isakov, V., 1990. Inverse source problems. American Mathematical Society, New York.

Ketzel, M., Omstedt, G., Johansson, C., Düring, I., Pohjola, M., Oettl, D., Gidhagen, L., Wåhlin, P., Lohmeyer, A., Haakana, M., Berkowicza, R., 2007. Estimation and validation of $\mathrm{PM}_{2.5} / \mathrm{PM}_{10}$ exhaust and non-exhaust emission factors for practical street pollution modelling. Atmospheric Environment 41, 9370-9385.

Künsch, H.R., 1989. The jackknife and the bootstrap for general stationary observations. The Annals of Statistics 17, 1217-1241.

Martín, F., Pujadas, M., Artinano, B., Gomez-Moreno, F., Palomino, I., Moreno, N., Alastuey, A., Querol, X., Basora, J., Luaces, J., et al., 2007. Estimates of atmospheric particle emissions from bulk handling of dusty materials in Spanish harbours. Atmospheric Environment 41, 6356-6365.

Monfort, E., Sanfélix, V., Celades, I., Gomar, S., Martín, F., Aceña, B., Pascual, A., 2011. Diffuse $\mathrm{PM}_{10}$ emission factors associated with dust abatement technologies in the ceramic industry. Atmospheric Environment 45, 7286-7292.

Muleski, G.E., Cowherd, C., Englehart, P., 1987. Update of fugitive dust emission factors in AP-42 Section 11.2. Technical Report. Midwest Research Institute, Kansas City, MO.

Muleski, G.E., Cowherd, C., Kinsey, J.S., 2005. Particulate emissions from construction activities. Journal of the Air \& Waste Management Association 55, 772-783.

Pant, P., Harrison, R.M., 2013. Estimation of the contribution of road traffic emissions to particulate matter concentrations from field measurements: a review. Atmospheric Environment 77, 78-97.

Sanfélix, V., Escrig, A., López-Lilao, A., Celades, I., Monfort, E., 2015. On the source inversion of fugitive surface layer releases. Part I. Model formulation and application to simple sources. Atmospheric Environment 109, 171-177.

Taylor, G.I., 1921. Diffusion by continuous movements. Proceedings of the London Mathematical Society 20, 196-211.

van Ulden, A., 1978. Simple estimates for vertical diffusion from sources near the ground. Atmospheric Environment 12, 21252129.

US EPA, 1995. Compilation of air pollutant emission factors. volume I: Stationary point and area sources. Fifth ed., US Environmental Protection Agency. Office of Air Quality Planning and Standards. URL: http://www.epa.gov/ttn/chief/ap42/ch13/final/ c13s02.pdf.

Venkatram, A., Fitz, D., Bumiller, K., Du, S., Boeck, M., Ganguly, C., 1999. Using a dispersion model to estimate emission rates of particulate matter from paved roads. Atmospheric Environment 33, 1093-1102.

Vrins, E., van Duuren, H., Janssen-Jurkovicova, M., 1994. Estimation of the emission rates of fugitive dust sources, in: Proceedings of 2nd Air Pollution Conference, Barcelona, Spain, pp. 157-168. 